\title{
CINCO REPRESENTACIONES DEL SUJETO HOMOSEXUAL EN LA NARRATIVA HISPANOAMERICANA (1895-1938) ${ }^{1}$
}

Five representations of the homosexual individual in Hispanic America (1895-1938)

\author{
Edson Faúndez V. * \\ Geraldine Villa Sánchez **
}

\begin{abstract}
RESUMEN
El sujeto homosexual emerge con intensidad en las ficciones novelescas hispanoamericanas hacia fines del siglo XIX, en un contexto dominado por dispositivos disciplinarios. Los personajes principales de Buen criollo (1895) de Adolfo Caminha, Los cuarenta y uno: novela crítico-social (1906) de Eduardo Castrejón, Pasión y muerte del cura Deusto (1924) de Augusto D'Halmar, El ángel de Sodoma (1927) de Alfonso Hernández-Catá y Hombres sin mujer (1938) de Carlos Montenegro portan en sus cuerpos las marcas de una transgresión intolerable para los poderes hegemónicos que procuran regular las alteridades. Los textos que analizamos permiten apreciar cómo los dispositivos disciplinarios médico, legal, religioso y estatal se transfiguran en instancias de vigilancia, encauzamiento y castigo de las posiciones de deseo que afectan el imperio de la heteronormatividad.
\end{abstract}

Palabras clave: poder disciplinario, alteridad, deseo homoerótico.

\footnotetext{
${ }^{1}$ Este artículo considera los resultados de uno de los capítulos de la tesis de Geraldine Villa Sánchez, becaria Conicyt, titulada "A los pies de la bestia enferma, un análisis de la figura del homosexual en cinco novelas hispanoamericanas: Buen Criollo (1895) de Adolfo Caminha, Los 41: novela crítico-social (1906) de Eduardo Castrejón, Pasión y muerte del cura Deusto (1924) de Augusto D’Halmar, El ángel de Sodoma (1927) de Alfonso Hernández-Catá y Hombres sin mujer (1938) de Carlos Montenegro". Programa Magíster en Literaturas Hispánicas, Universidad de Concepción. Profesor guía: Edson Faúndez V.

* Facultad de Humanidades y Arte, Departamento de Español, Universidad de Concepción. Concepción, Chile. Correo electrónico: efaundez@udec.cl

** Facultad de Humanidades y Arte, Magíster en Literaturas Hispánicas, Universidad de Concepción. Concepción, Chile. Correo electrónico: geraldinevilla@outlook.com

Artículo recibido el 19 de marzo de 2018. Aceptado el 31 de octubre de 2018.
} 


\begin{abstract}
The homosexual individual emerges intensely in Hispanic American fiction novel towards the end of the $19^{\text {th }}$ century, in a context dominated by disciplinary devices. The main characters of Bom-Crioulo: The Black Man and the Cabin Boy (1895) by Adolfo Caminha, The 41: A Socio-Critical Novel (1906) by Eduardo Castrejón, Pasión y muerte del Cura Deusto (1924) by Augusto D'Halmar, El ángel de Sodoma (1927) by Alfonso Hernández-Catá, and Hombres sin mujer (1938) by Carlos Montenegro bear in their bodies the brands of a transgression intolerable for the hegemonic powers that try to rule alterities. The texts we analyse allow us to see how the medical, legal, religious, and state disciplinary devices become agencies of surveillance, channeling, and punishment of the positions of desire that affect the empire of heteronormativity.
\end{abstract}

Keywords: disciplinary power, alterity, homoerotic desire.

\title{
1. Un nacimiento 'anormal': una bestia agazapada en la literatura hispanoamericana
}

El examen de las primeras representaciones literarias del sujeto homosexual $^{2}$ en la novelística hispanoamericana es clave para comprender los procedimientos de configuración y de exorcización de la alteridad homosexual dentro del marco general de las sociedades normalizadoras. La emergencia en el espacio literario del sujeto cautivo del deseo homoerótico se relaciona con el sueño de la literatura de hacer visible y audible las secretas "desviaciones" de vidas oscuras, mínimas y cotidianas de hombres y de mujeres infames, según lo propone Michel Foucault en La vida de los hombres infames (1996). Los sistemas literarios de representación realista y naturalista posibilitan en Hispanoamérica la irrupción de personajes infames cada vez más alejados de

\footnotetext{
${ }^{2}$ El término 'homosexual' es obviado en todas las novelas seleccionadas. La razón por la que, a pesar de ello, se emplea en el análisis de textos obedece a dos motivos: por un lado, la dicotomía establecida entre 'homosexual' y gay (enfermedad/vida, simplificándolo al máximo) permite un primer acercamiento que facilita su diferenciación respecto de la narrativa actual; por otro lado, estas representaciones literarias remiten a un sistema heteronormativo que, reafirmado por principios médicos, religiosos y judiciales, defiende la existencia de una "substancia homosexual' orgánica o psíquica común a todos los hombres con tendencias homoeróticas" en razón de la cual pueden ser discriminados y eliminados (Cornejo, 2009, pp. 143-144). Esta 'identidad' homosexual que caracterizará al sujeto disidente que emerge en este contexto (siglos XIX-XX) debe ser comprendida como una mera extrapolación y generalización; la 'homosexualidad' debe continuar considerándose como una realidad lingüística e histórica particular.
} 
la heteronorma ${ }^{3}$. La novela, por lo mismo, se convertirá en el espacio fictivo propicio para la revelación del transgresor secreto de la diferencia sexual. Los textos que analizaremos ficcionalizan el encuentro de la alteridad homosexual con las sociedades que intentan homogeneizar a los individuos sobre la base de la heteronormatividad, atacando aquellas desviaciones que suponen una perturbación inaceptable para los poderes y la moral hegemónicos.

El corpus seleccionado consta de cinco novelas hispanoamericanas, escritas desde fines del siglo XIX hasta las primeras décadas del siglo XX: Buen Criollo (1895) del escritor y periodista brasileño Adolfo Caminha (1867-1897); Los cuarenta y uno: novela crítico-social (1906) de Eduardo A. Castrejón, seudónimo que usaría el general mexicano Mariano Ruiz Montañés (1846-1932) 4; Pasión y muerte del cura Deusto (1924) del chileno Augusto Goemine Thomson (1882-1950), posteriormente conocido como Augusto D'Halmar'; El ángel de Sodoma (1927) del escritor y diplomático hispanocubano Alfonso Hernández-Catá (1885-1940) ${ }^{6}$; y Hombres sin mujer (1938)

\footnotetext{
${ }^{3}$ Antonio Tudela Sancho (2012) plantea que la heterosexualidad, como construcción social, se sustenta tanto en "el varón (dominus, pater familias, gobernante), la familia (igualitaria, cristiana, virtuosa), el propio contrato heterosexual (entre los dos sexos, monógamo, fiel)" como en la exclusión de "la mujer (...), la relación sexual primitiva (desigualitaria, islámica, presa del placer o del instinto brutal), los peligros de la inversión y la perversión de la heterosexualidad" (p. 13).

${ }^{4}$ El seudónimo no fue reclamado públicamente por ningún escritor. La investigación de Robert Mckee Irwin (2013) identifica, sin embargo, al general Mariano Ruiz Montañés (1846-1932) como el autor de la novela en estudio. Esta destacada figura se distingue, en el contexto de su época, por su participación política y militar en diversos conflictos mexicanos, así como por su gran afición por la historia, reflejada en su producción escritural.

${ }^{5}$ Augusto Goemine Thomson nace en Chile como hijo ilegítimo de una chilena acomodada y un marino francés dado a la fuga. Si bien su proyecto de la Colonia Tolstoyana (1904-1905) no resulta exitoso, es en esta instancia donde, unido a Fernando Santiván, adopta el seudónimo que lo hará conocido: Halmar (más tarde D’Halmar). La amistad entre ambos se disolvería debido al matrimonio entre Santiván y la hermana de D'Halmar, hecho que aparece recurrentemente ficcionalizado en su escritura. Su afición al viaje y su constante errancia definirán tanto su vida como su obra, caracterizada, entre otros aspectos, por un particular gusto por Oriente y lo exótico.

${ }^{6}$ Alfonso Hernández-Catá trabaja como embajador en Europa y América Latina, hecho que favorece el florecimiento del sentir cosmopolita que caracteriza su obra. Gran admirador de José Martí, desarrolla con especial talento la cuentística bajo la influencia de Poe y Maupassant. Contrae matrimonio en 1907 con Mercedes Lila, la hermana de su íntimo amigo Alberto Insúa. La figura de Benito Pérez Galdós cobra especial importancia en su carrera impulsada, ya en su juventud, por el propio español.
} 
del hispano-cubano Carlos Montenegro (1903-1953)7.

Algunas de estas novelas, pioneras en la construcción literaria del sujeto homosexual, suelen ser rechazadas debido a su marcada homofobia, simplificación o conservadurismo. Ellas, en la medida en que presentan en primer plano al personaje homosexual ${ }^{8}$, fundamentalmente oscurecido en la narrativa decimonónica, permiten, no obstante, apreciar las operaciones que los poderes disciplinarios realizan sobre las posiciones de deseo homoerótico que transgreden el encauzamiento deseante promovido por las sociedades normalizadoras. El diálogo intertextual que proponemos revela asimismo las fisuras de este tipo de sociedades, que intentaron, entre otros aspectos, señalar el deseo desviado, construir la diferencia y producir estrategias de regulación o expulsión de las alteridades radicales.

La nueva física del poder, expuesta en la obra foucaultiana, erige el cuerpo como objeto de conocimiento e intervención privilegiado a partir del despliegue de una óptica especial (panoptismo) que permite el ejercicio de una vigilancia sistemática y ubicua; de una mecánica característica (disciplinaria), encargada de la localización, movilización y utilización de los individuos mediante un control perpetuo; y de una fisiología diferente (normalizadora) que determina tanto la norma como el campo de regularidad que la define (Foucault, 1996, pp. 49-50). Las disciplinas atrapan de este modo al sujeto en una red de relaciones de poder que pretende (re)configurarlo en tanto "cuerpo productivo y cuerpo sometido", construido en torno a los conceptos de utilidad y docilidad (Foucault, 2002, p. 26). El funcionamiento del poder disciplinario respecto de la irrupción de deseos que perturban el orden establecido puede

\footnotetext{
${ }^{7}$ Carlos Montenegro nace en España, trasladándose a corta edad a Cuba. Luego de abandonar el colegio y vivir brevemente en Argentina, se dedica a viajar y trabajar en diversos rubros; será en su regreso a la isla (1919) cuando, debido al homicidio que comete en medio de una riña callejera -supuestamente en defensa propia-, ingresa a prisión con una pena de más de catorce años (de los cuales cumple doce). Comienza a escribir dentro de presidio, con la ayuda de José Zacarías Telliet, en un intento por obtener su prematura libertad; a pesar de no alcanzarla, se granjea gran reconocimiento a nivel nacional e internacional. Este hecho propicia su comunicación epistolar con Emma Pérez, gran admiradora, quien termina por convertirse en su esposa.

${ }^{8}$ El comentario de textos se centra fundamentalmente en el personaje considerado como el protagonista de cada novela: Amaro (Buen Criollo), Ninón (Los cuarenta y uno...), Deusto (Pasión y muerte...), José-María (El ángel de Sodoma) y Pascasio (Hombres sin mujer).
} 
advertirse con claridad en las novelas que nos ocupan, pues en ellas los personajes disidentes de la heteronorma se aprecian circundados por todo tipo de instituciones y estrategias disciplinarias.

\section{Amo y esclavo: sometimiento y expresión del deseo frente a la alteridad}

Buen criollo (1895) de Adolfo Caminha ahonda en el régimen machista y el código disciplinario que sustenta la vida en la marina, con la finalidad de contener y (re)conducir la energía de los hombres hacia el trabajo productivo; toda forma subsidiaria de placer (masturbación, polución nocturna, relaciones entre sujetos de un mismo sexo, etc.) queda así totalmente excluida. La introducción del protagonista (Amaro) como el "tercer preso", en la instancia que antecede su castigo, no solo permite apreciar su imponente fuerza y resistencia física, cualidades superiores a las del resto de la tripulación, sino que sitúa el cuerpo como centro neurálgico del sistema disciplinario desplegado en la novela (Caminha, 2005, p. 20). La esclavitud a la que es sometido Amaro, ininterrumpida a pesar de su movilidad social, experimentada ora en el cañaveral, bajo el sistema esclavista, ora en la marina, con sus normas y reglamentos, explicita de igual forma la activa circulación del poder, su tránsito indiferenciado por todo el cuerpo social y su particular naturaleza metadisciplinar, así como el complejo proceso identitario y de reafirmación al que Buen criollo se ve sometido como 'hombre' (Nunes et al., 2015, pp. 202-203).

$\mathrm{Su}$ apodo, Buen criollo, resalta su (in)docilidad; aunque su obediencia y laboriosidad inicial recuerdan a aquel mítico 'buen salvaje' (Arévalo, 2011), sometido por el poder civilizador e 'incluido' por ello en la sociedad, es claro que ni su relación con Aleixo ni su correspondencia con el modelo hegemónico de virilidad bastan para hacerle abandonar tal posición subordinada: “«Siempre ha sido enemigo de toda norma de vida. Hoy manso como un cordero, mañana tempestuoso como una fiera. Cosas del carácter africano»" (Caminha, 2005, p. 74). Amaro, desobediente, ebrio y sodomita, se erige entonces como el máximo fracaso de la disciplina militar al tiempo que se convierte en el engranaje que sustenta la necesidad de su mantención y recrudecimiento. Este salto desde 
la condición de alteridad regulada hacia la de alteridad radical ${ }^{9}$ (Baudrillard y Guillaume, 2000) terminará con su expulsión definitiva.

Buen criollo ejerce "una suerte de violencia simbólica" sobre Aleixo por medio de estrategias que promueven su feminización y, por ende, su sometimiento, despertando en el joven "un afán de pasividad" que permite la entrada de Amaro al orden que siempre ha buscado excluirlo (Nunes et al., 2015, p. 206; Caminha, 2005, p. 54). Su ahínco reafirma, empero, su posición: "ya sabemos que, en el orden simbólico, quien se cree superior es automáticamente inferior; hay una reversibilidad que le asegura siempre la peor parte" (Baudrillard y Guillaume, 2000, p. 97). La relación entre ambos, aún bajo los parámetros helénicos, con un proceso de enseñanzaaprendizaje y un sistema de retribución, fracasa debido a la aprensión de Amaro, quien desde el inicio experimenta una fascinación enfermiza por el joven, pretendiendo retenerlo a su lado (Howes, 2005, p. 184). Los esquemas relacionales se modifican radicalmente frente a esta actitud sumisa entendida como debilidad: Amaro, a un tiempo bestia, homosexual y mulato, se sitúa por debajo de Aleixo en tanto varón, heterosexual y 'blanco' (Nunes et al., 2015). Buen criollo, atrapado en medio de sus instintos y anhelos, retorna rápidamente a su condición inicial (esclavo/animal), atacando y dando muerte a Aleixo al enterarse de su engaño. La presencia de Amaro suscita por ello la intervención de la ley, excluida no obstante de la narración ${ }^{10}$. La novela expone

\footnotetext{
${ }^{9}$ El sujeto que, en tanto alteridad regulada, es factible de ser comprendido y asimilado, a pesar de su diferencia, ve radicalizada su condición a través de la expresión de su deseo homoerótico, convirtiéndose en un ser "inasimilable, incomprensible e incluso impensable", negado e invisibilizado sistemáticamente (Baudrillard y Guillaume, 2000, pp. 12-13). La excesiva proliferación de mecanismos de control y normalización señala a todo aquel que se aleje del modelo universal de ser humano (hombre, caucásico, joven, sano, ciudadano, heterosexual), aplacando su caótica diferencia existencial (Baudrillard y Guillaume, 2000, p. 16).

${ }^{10}$ Caminha se habría inspirado, según Robert Howes (2005), en dos reportajes de la época divulgados en los medios brasileños, especialmente en el hecho acaecido en Portugal en 1886: un cadete -Marinho da Cruz- dispara a su colega -António Candido Pereira-, con quien supuestamente mantenía una relación amorosa, impulsado por los celos. El culpable es remitido a una institución psiquátrica (al atribuir sus actos a un estado de demencia temporal), sin embargo, en un segundo juicio se logra revocar esta sentencia, logrando su destitución y condena. Si bien Caminha no menciona explícitamente ninguna de sus fuentes, las alusiones parecen bastante claras. Aún más: la misma duda que asedia al tribunal (¿celos o locura?) poseerá al lector que reflexiona sobre el crimen de Amaro.
} 
entonces la imposibilidad de concebir la alteridad como algo distinto a la monstruosidad. El sujeto homosexual, amenaza siempre latente, se constituye bajo el más estricto control, de modo que todo amago de resistencia conlleva su inevitable y definitiva expulsión. La escritura naturalista de Buen criollo se caracteriza por la inclusión de deseos perturbadores que son sometidos a rituales de exorcismo. La novela se convierte así en un territorio dominado por dualismos irreconciliables, motivo por el que la posición de deseo homoerótico es expulsada del entramado social ficcionalizado.

\section{El homosexual suicida: el señorito bajo el asedio de Sodoma}

La vigilancia a la que la ciudad-panóptico somete a José-María en $E l$ ángel de Sodoma (1927) de Alfonso Hernández-Catá enfrenta constantemente a los Vélez-Gomara con la figura metamorfoseada de su progenitor; al intentar contradecir la voluntad paterna, dejando fluir simbólicamente su deseo, José-María se transforma en una figura sumisa y, al mismo tiempo, insubordinada, por lo que debe ser exterminada: “ ¡La madrecita alabada por todos era un monstruo, un lirio de putrefactas raíces!" (Mejías-López, 2007: s/n; Hernández-Catá, 2011, p. 23, cursiva en el original). Su ambigua constitución física y psíquica, advertida tanto por él mismo como por los demás, cifran lo femenino como su principal ‘aberración': el reconocimiento de su naturaleza indiferenciada suscita terribles abusos que el joven ejercerá sobre su cuerpo para acallar sus deseos, imponiéndose un estricto régimen que abarca desde su forma de caminar y vestir hasta cantidades enfermizas de trabajo, rigurosas rutinas físicas e incluso la adopción de un ascetismo ridículo. Las operaciones del personaje buscan obturar su deseo y son equivalentes a las operaciones textuales de la escritura mimética de Hernández-Catá que construyen un espacio literario que funciona como una verdadera cárcel del deseo en interdicto.

Estas operaciones, efectuadas sobre el cuerpo como efectos directos del poder disciplinario que intenta visibilizar y castigar al sujeto "desviado", estructuran una especial relación de aniquilación y de exclusión en la intimidad del protagonista: su ansia de vivir, manifiesta en su cada vez más despierta 
sexualidad, se enfrenta así a su deseo de muerte, exigencia social nacida de su monstruosidad (Galdo, 2000, p. 29). José-María busca por ello acabar con una existencia que primero considera aberrante y, luego, innecesariamente llena de "abnegaciones" y "resistencias" que debe atravesar inútilmente (Hernández-Catá, 201, p. 68). Este pensamiento sobre su propia muerte (re) surge fugazmente a lo largo de toda la narración; si bien José-María parece aceptarse, el suicidio, como la máxima expresión de violencia sobre el cuerpo que se aleja de la construcción social heteronormativa, supone que el deseo de aniquilación subsiste en todo momento. Es el único deseo cuyo despliegue permite el espacio novelesco: el exterminio simbólico de la alteridad radical.

Algunos espacios limítrofes -el circo, el muelle, la estación de trenes, París- denotan, en este sentido, cierta liberación de los impulsos anteriormente reprimidos por el poder patriarcal, mientras que otros refuerzan su influencia al constituirse en panópticos que cercan al protagonista y sus deseos: el banco, su casa, su habitación (Galdo, 2000, p. 30). El ambiente circense, encarnado en la figura del trapecista, resulta esencial en el despertar de la 'anormalidad' de José-María, desplazándolo hacia la tan ansiada libertad. El apego del joven a su apellido y, por ende, a su ciudad, resulta no obstante perjudicial: al decidir conservar su nombre, pese a sus anteriores aprensiones, facilita la detección de su ubicación en París y promueve un nuevo asedio moral sobre su existencia, precipitándolo a la muerte.

El título de la novela catiana remite de igual modo a la tradición judeo-cristiana y su simbología (Mejías-López, 2007: s/n). La expresión de la homosexualidad como pecado y la muerte como castigo (Sodoma) suscita y legitima el ataque social, obligando al protagonista a adscribir a una disciplina religiosa basada en el despertar de la culpa y la aplicación del castigo físico como freno a su voluptuosidad. Una creciente paranoia se desarrolla a partir de sus difíciles vivencias; su particular situación en la ciudad, como primogénito de una de las familias fundadoras, pero también su singularidad le harán suponer repetidamente que su 'condición' es un 'secreto a voces' que en cualquier momento llevará a su familia a la mayor deshonra. La novela refleja así el sometimiento individual de un sujeto que solo puede verse en 
la imagen que produce el orden y la moral establecidos; se siente por ello monstruoso y busca, por todos los medios, contenerse a sí mismo: lastimando su cuerpo, destruyendo su autoestima y sometiéndose a un estrés constante, el deseo de José-María no logrará manifestarse más que de forma incipiente y difuminada, disolviéndose completamente en la estación parisina.

\section{El baile de los jóvenes infames: afeminamiento y degeneración en la aristocracia mexicana}

Los cuarenta y uno: novela crítico-social ${ }^{l 1}$ (1906) presenta un claro ejemplo del sujeto homosexual como figura aberrante (para el orden establecido) y, especialmente, de la reacción de la sociedad ante su presencia. La Gran Redada “"sienta jurisprudencia”" al fomentar la intervención del poder estatal que somete a los 'maricones' al escarnio público y la acción policial (Monsiváis, 2013, p. 61). El "espacio represivo", delimitado arbitrariamente por "“las faltas a la moral y las buenas costumbres", se encargará de aportar la vigilancia y el castigo necesarios para mantener controlado al infractor que atenta contra la imagen de la familia y la mujer exaltadas por la heteronorma (Monsiváis, 2001, pp. 38 y 50; Contardo, 2011, p. 62).

La aparición de 'los cuarenta y uno' constituye un acto fundacional que "inventa la homosexualidad en México", dentro de un marco social signado por la moralidad defendida por el porfiriato, a partir de un elemento esencial: el travestismo de los personajes no es más que un signo vergonzante que se perpetúa a través del vocabulario con el que el autor hace referencia a este grupo de "“cocottes de toilette a la pompodour"” (Monsiváis, 2001, p. 311; Castrejón, 2013, p. 74, cursiva en el original). La figura del aristócrata surge, en este contexto, como un "Ser de Ambiente", caracterizado por una particular "aptitud para el relajo" y un gran "ánimo de fiesta", rasgos expresados a partir de diversos dispositivos humorísticos, aunados a un floreciente deseo

\footnotetext{
${ }^{11}$ La novela de Castrejón aborda la homosexualidad como "un asunto subordinado, narrativa y axiológicamente"; el autor parece emplearla como un "pretexto" para señalar la naturaleza degradada y decadente de la aristocracia - detrás de la cual se oculta el porfiriato- en relación con la clase obrera, adjudicando a la primera el peor crimen moral -la homosexualidad-, pues sabe que nadie sería capaz de defenderlo (Marquet, 2006: 48-49).
} 
cosmopolita y un fuerte "culto por la apariencia" que, si bien permiten un amago identitario, no dejan de señalar su naturaleza risible y monstruosa (Monsiváis, 2001, pp. 326-327). La risa, desde esta perspectiva, funciona como uno más de los intensificadores del poder dominante: señala, humilla y corrige a quien se ha desviado de la norma". Funciona, por lo tanto, como uno de los recursos fundamentales para producir el corte de los flujos deseantes que perturban los binarismos sociales que defiende la máquina axiológica del relato.

El número 000 de la calle de la Paz, donde se realiza la fiesta organizada por el grupo de Ninón, actúa a un tiempo como asilo y patíbulo: la conjunción de lo público (figuras nobles, respetables y admiradas) y lo privado (seres abyectos y vergonzantes) será la causa de la desestabilización social que impulsa la caída de los personajes en el tortuoso camino de la ignonimia. Los sujetos homosexuales, bajo este peligro inminente, solo tienen dos opciones: "O la total integración moral o social, o la permanencia en el escándalo" (Mayer, 1999, p. 91). Esta es la causa por la que, aún en el ámbito privado, los personajes "se perciben bajo el binarismo heterosexual del hombre y/o la mujer" mientras que en el ámbito público deben adaptarse a los códigos burgueses de la doble moral (Del Toro, 2015, pp. 78-79). Ninón representa el más claro ejemplo pues no solo se compromete con una acaudalada señorita, para buscar aumentar su dinero y su honra, sino que procura mantener una imagen 'masculina', posibilitando un proceso de empoderamiento que le permitirá superar su estigmatización y acceder a una pronta 'rehabilitación' (Del Toro, 2015, p. 70).

El detective Mano de Alacrán, contratado por Judith, la prometida de Ninón, será el encargado de revelar tanto la celebración de esta fiesta como la verdad de sus asistentes, impulsando el posterior proceso de condena social. Si bien el tratamiento entregado por el Gobernador inspira una alabanza general, el actuar de la ley, fragmentado e insuficiente, no logra compararse con el dominio conseguido por medio de la injuria: "llamar a alguien «marica», «maricueca» o «maricón» no es simplemente describirlo o informar sobre un aspecto de su vida, es un ejercicio de poder -y control- sobre esa persona" 
(Contardo, 2011, p. 117). Este sistema infamante -variable, personalizado, coherente a la falta y gradual en su aplicación-, basado en la "reacción espontánea de la sociedad", deriva de un fuerte e infalible sentimiento del honor que, altamente reaccionario, funciona mediante un costo mínimo y una efectividad total (Foucault, 1996, p. 42). La aristocracia mexicana expulsa inmediatamente de su seno a aquellos que no son capaces de regirse por el principio de la doble vida. Pocos serán los asistentes que logren, debido a ello, regresar impunes para reincorporarse a las filas de la clase privilegiada.

El ataque al pudor cometido por el grupo de Ninón recibe una pena provisional que denota a un tiempo cierta improvisación y una marcada premura: el castigo a "los lindos señoritos" no solo consiste en limpiar propiedad pública en un desfile en el que se entremezclan faldas, bigotes, zapatos de tacón y movimientos insinuantes, sino también en un destierro indefinido en un territorio destinado solo 'para hombres': el ejército (Castrejón, 2013, p. 109, cursiva en el original). La inclusión de estos sujetos aristócratas, ociosos y parásitos por definición, como lo resalta la novela, en un dispositivo disciplinario pretende ejercer sobre ellos un nuevo y necesario efecto regularizador que los aleje de la 'degeneración' sexual y los transforme en sujetos útiles para las expectativas del sistema. Esta pena, desproporcionada debido a la perplejidad causada por la presencia del monstruo moral, surge de la confusión que suscita la inexistencia de un crimen que cifre, como tal, el comportamiento de los cuarenta y uno, censurado por la moral establecida. La novela expresa así, a partir de un caso de acoso particular, cómo reacciona la sociedad frente al sujeto homosexual, asediado por mecanismos policiales, legales y sociales que terminan por expulsarlo del seno de la nación.

\section{Un cordero para el sacrificio: erotismo y sacerdocio}

La Giralda, "Fortissima turris nomen Domine", marca en Pasión y muerte del cura Deusto (1924) el destino del sacerdote, protagonista del relato, desde su llegada a Sevilla; la vigilancia que ejerce sobre la ciudad, bajo el signo de la moralidad y la religiosidad, la transforma en el ojo avizor de la divinidad y de los hombres (D’Halmar, 2014, p. 474, cursiva en el original). 
La aparición de Pedro Miguel activa, por otra parte, las redes de vigilancia en que se apoya el poder eclesiástico; los feligreses de la parroquia de San Juan de la Palma y los miembros del clero, a los que pronto se une el resto de la ciudad, sumen a Deusto en una continua desazón e intranquilidad.

La relación "quasi-pederástica" sostenida entre Pedro Miguel y Deusto provoca la colisión entre el atractivo y la sexualidad del primero y los ideales del segundo, "llevado por una obsesión de pureza típicamente católica" (Villanueva-Collado, 1996, pp. 5-6). Su vínculo, aún "desexualizado, sublimado y sacralizado", despierta tempranamente la intervención religiosa y social, pues la 'falta' no solo recae en la naturaleza de su deseo, sino también en las condiciones sociales y morales de los protagonistas, apartados del "discurso amoroso social" tradicional (Domínguez, 2001, s/n). La moral cristiana, sustentada en la familia y en una concepción binaria que afirma tanto la correspondencia sexo/genérica del sujeto como la división entre lo sagrado y lo profano, excluye al homosexual debido al quiebre simbólico que supone afrontar y contradecir los mandatos divinos: continuar la estirpe, ya por la vía sanguínea o la espiritual (Jambrina, 2000, p. 2).

Deusto, como sacerdote, debe seguir una estricta disciplina religiosa, marcada por la abnegación, el arduo trabajo, el asedio de la culpa y el castigo constante como forma de resarcimiento, sometiendo su cuerpo y espíritu mediante actos que van desde el simple ayuno hasta las privaciones más exageradas. Su vida conlleva, empero, un peso mayor al emular de manera sacrílega la figura de Cristo y su sacrificio, abarcando desde el inicio de su evangelización hasta el momento de su Pasión. Las visitas que Deusto realiza, primero al circo junto a Pedro Miguel y luego al teatro para observar a escondidas la presentación del joven, sin la protección de la sotana, lo enfrentarán, en su condición de hombre, a la tentación y a su destino. La presencia del Aceitunita incluso impulsa decisiones que afectan directamente su curato, como el despido de Pajuela o el posterior recibimiento del joven, acogida con tintes de secuestro, a pesar "del escándalo del teatro [y] el suicidio frustrado” cometido por Pedro Miguel (D’Halmar, 2014, p. 630). Su presencia simboliza así tanto la salvación de Deusto y su reencuentro con Dios como la 
amenaza de su castigo eterno.

Deusto se cría bajo la influencia de un retablo que presenta la imagen del Buen Pastor, esperando poder emularlo durante el ejercicio de su labor en San Juan de la Palma. Las innovaciones que el vasco se apresura a implementar buscan, en este sentido, predicar con el ejemplo: "somos nosotros, los pastores, los que debemos guiar y no seguir al rebaño" (D’Halmar, 2014, p. 483). El cristianismo exige que el pastor conozca y cuide de cada oveja mediante "un intercambio y una circulación compleja de pecados y méritos", esto es, un lazo moral y vital que los une infaliblemente (Foucault, 1996: 189). Este mismo objetivo lo lleva más tarde a centrarse en Pedro Miguel para devolverlo al redil, tarea que finalmente queda inconclusa cuando el sacerdote termina por perderse junto al trianerillo, quien nubla su pensamiento y confunde su alma, desorientando la brújula moral que debía suponer su presencia para Sevilla (D’Halmar, 2014, p. 644). El desenlace y desarrollo trágico de la trama, junto a la ambigüedad que reviste a Pedro Miguel -a un tiempo niño cariñoso y hombre seductor-permite establecer al menos dos tipos de recepción lectora: "la una enjuiciadora, de lectores que necesitan ver al homosexual como viborilla y por ende portador de desgracia, la otra simpática, cómplice, de lectores entendidos que practican una lectura 'entre nos' y se identifican con el desenlace patético" (Molloy, 1999: 275). La novela se transforma así en un símbolo invertido de colonización al situar "el deseo homosexual en un 'afuera' exótico y, con el mismo gesto, traerlo de vuelta a casa, una casa que los nacionalistas hispanoamericanos y defensores de la hispanidad latina y 'pura' no reconocerían y menos reclamarían” (Molloy, 1999, p. 278).

D'Halmar construye un espacio discursivo en el que confluyen el poder y la abyección, expresando de manera patente cómo la fuerza, control y autoridad que, a partir de la moral judeo-cristiana, se ejerce sobre los cuerpos de los sujetos o sobre sus almas, también se genera y mantiene a partir de ellos. La novela escrita en la época en que su autor descubre las sensualidades de España tiende delgados puentes entre los dualismos poder y placer, por lo que éstos se exigen mutuamente, estremeciéndose así el orden binario que 
sustenta la heteronormatividad.

\section{Pena de muerte: la tormentosa vida carcelaria de los 'hombres sin mujer'}

El presidio es el modelo disciplinario por excelencia debido a su naturaleza "omnidisciplinaria": por una parte, pretende abarcar "todos los aspectos del individuo"; por otra, su acción es ininterrumpida y despótica (Foucault, 2002, p. 216). Su funcionamiento incluye una serie de medidas aislamiento, moralización, adopción de un soporte parapenal y creación de un archivo individual para cada criminal- que aspira a transformar al sujeto en un ser factible de ser (re)integrado al campo social. El encierro busca circundar la vida del individuo al permitir que el poder se extienda y circule por doquier, desde las máximas autoridades hasta el más reciente recluso. El régimen de trabajo, la división de los sujetos y su distribución en las galeras, junto a la rutina cotidiana que asedia a los presidiarios, aunados a una mirada panóptica empleada como forma privilegiada de supervisión convierte a cada recluso de Hombres sin mujer ${ }^{22}$ (1938) en parte de la maquinaria disciplinaria.

El sistema jerárquico que estructura la ficción gira en torno al "capital pájaro" o "potencial sexual afeminado" que poseen ciertos sujetos (Gallardo, 2010, p. 108). La juventud y belleza, pero también la "debilidad e indefensión", rasgos estereotipadamente femeninos, los dotan de una "naturaleza en transición" que constituye uno de los bienes más valiosos del presidio (Montenegro, 2008, pp. 172 y 237). La pirámide social que rige la vida carcelaria se construye sobre la base de la cercanía que mantiene cada personaje con el ideal de masculinidad hegemónico ${ }^{13}$; desde aquel que obvia

\footnotetext{
${ }^{12}$ Montenegro, a raíz de la participación del criminólogo español Luis Jiménez de Asúa en un congreso realizado en torno a la reforma penal (1936), decide escribir un breve relato para exponer su perspectiva. Sin embargo, la narración adquiere una complejidad y extensión mayor a la esperada, convirtiéndose en novela (Pujals, 1980, p. 42; cit. en Gallardo, 2010, p. 109).

13 Este concepto es desarrollado por Connell (1995) para explicar la existencia de una masculinidad idealizada, erigida en un contexto específico, que se opone a otras 'masculinidades' desarrolladas por cada sujeto en su cotidianeidad, más o menos alejadas de este ideal instaurado socialmente. Esta idea enfatiza que la masculinidad está en constante (re)construcción, razón por la cual siempre necesita ser reafirmada, tanto por el propio sujeto como por sus pares (Messerschmidt, 2005, p. 198; cit. en Gallardo, 2010, p. 122).
} 
toda relación amorosa con otro interno hasta quien se hace pasar por pájaro para obtener algún beneficio, todo presidiario termina por ser encasillado como "macho" o "marica" dependiendo de la forma en que invierta su capital (moral, social, 'pájaro' y/o económico) para mantener o cambiar tales representaciones (Bejel, 2006, p. 279; Gallardo, 2010, p. 126).

El protagonista, Pascasio Speek (preso $n^{\circ}$ 5062), destaca en este sentido por mantenerse célibe en su confinamiento y exhibir una conducta ejemplar, sustentada en la domesticación de sus impulsos y la repetición de las normas morales válidas fuera de presidio, en aras de reducir su condena; desde el inicio, es claro que uno de los mayores miedos o reticencias de Pascasio es "verse envuelto en un enredo de sodomitas", lo que podría poner en peligro las "ocho papeletas de buena conducta" obtenidas hasta entonces (Montenegro, 2008, pp. 24 y 28). La vida en confinamiento comienza no obstante a desdibujar sus esperanzas, confundir el deseo y despertar su rostro más transgresivo, pues el heroico camino forjado por Pascasio se encontrará con una gran dificultad: la cárcel en su totalidad, desde el objeto más mínimo hasta el lenguaje, constituye un ambiente plagado de lubricidad y muerte.

$\mathrm{Si}$ bien la prisión permite ciertas concesiones al régimen heteronormativo, validando nuevas relaciones entre los sexos (homoerotismo), mantiene una particular desvalorización y discriminación hacia los sujetos 'afeminados' de la Aldecoa (homofobia); es decir, permite a un tiempo "expandir los roles sexuales permitidos" y mantener una "estructura genérica desigual" fundada en "la seducción, el chantaje, el descrédito y la violación de quienes son considerados débiles, los homosexuales o 'leas'" (Gallardo, 2010, pp. 117-118; Saumell, s.f., s/n). La homosexualidad se convierte entonces en una práctica más dentro del sistema, pero también en una forma de resistencia al impulsar el nacimiento de relaciones amorosas que intentan superar la lógica imperante (Bejel, 2006, p. 279). La identidad de Pascasio fluctúa así entre el amor y el "reto hipermasculino", movimiento oscilante que lo lleva a situarse en la cima para luego caer hasta el abismo, arrastrado por la fuerza del capital pájaro de Andrés, convirtiéndose en fuente de "golpizas, encierro adicional, asesinato, suicidio" (Gallardo, 2010, pp. 126-127; Saumell, s.f., 
$\mathrm{s} / \mathrm{n}$ ). La conclusión novelesca -Pascasio falleciendo en los brazos de Braicifra en este sentido una paradoja: por un lado, señala la supremacía de un machismo criticado a lo largo del relato; por otro, representa su decadencia y su ruptura (Bejel, 2006, p. 284). Desde esta perspectiva, la novela provoca la crisis de los binarismos que sostienen las primeras representaciones del sujeto homosexual estudiadas en este artículo y, consecuentemente, posibilita la emergencia de un espacio textual donde los flujos de deseo que circulan entre los dualismos no pueden ser contenidos. Este tratamiento singular de la posición de deseo que perturba el orden establecido cifra de alguna manera la quiebra de la organización del deseo en el entramado social disciplinario y en las ficciones miméticas (realistas y naturalistas) que lo representan.

El rechazo que el 'hombre' experimenta respecto de estos seres 'abyectos' y la violencia que supone todo amago de acercamiento tiene su sustento en un discurso que depende de "tres negaciones básicas que debe probar constantemente: que no es mujer, que no es bebé y que no es homosexual" (Badinter, 1996, pp. 50-53; cit. en Cabezas y Berná, 2013, p. 785). Las regulaciones y estrategias de control ejercidas sobre los cuerpos pretenden evitar cualquier mínima “superposición” que pueda atentar contra la ficción de totalidad y homogeneidad que rodea la masculinidad: las prácticas misóginas y de alterización suponen en este sentido un método eficaz de preservación (Pereda, 1991, p. 45; cit. en Cabezas y Berná, 2013, p. 794). La novela expone no obstante el fracaso del ideal del poder disciplinario perseguido por la sociedad normalizadora: erradicar toda expresión de alteridad. Ni siquiera el sistema de trabajo instaurado o la constante presencia de los encargados posibilitarán algún tipo de moralización pues, mientras el primero sirve como método de retribución e intercambio de servicios (generalmente sexuales), los segundos destacan por su incompetencia, aprovechamiento y sadismo (Gallardo, 2010, p. 112). La novela de Montenegro desvela así los mecanismos penitenciarios y judiciales que acechan a todo sujeto dentro del espacio carcelario, saturado de violencia, deseo y muerte, definiendo sus relaciones tanto con su propio cuerpo e interioridad, así como con los de los otros. Escritura que desarma los 
dualismos y libera los flujos de deseo más perturbadores.

\section{Encauzar el deseo: el sujeto homosexual bajo el escrutinio del poder disciplinario}

Las novelas analizadas -Buen Criollo (1895), Los cuarenta y uno: novela crítico-social (1906), Pasión y muerte del cura Deusto (1924), El ángel de Sodoma (1927) y Hombres sin mujer (1938) - iluminan una cartografía del deseo transgresivo, cuyas líneas se irán redefiniendo con el pasar de los años. El plan escritural declarado originalmente por sus autores, dentro del marco de sus respectivos campos culturales y estéticos, las convierten en ficciones que exponen y problematizan una realidad oscurecida por la literatura precedente (nos referimos a los años anteriores a la publicación de Buen Criollo), factor que las provee de un estatus bastante ambiguo: por una parte, abordan la homosexualidad de sus protagonistas según los cánones heterosexuales de la época -lo homosexual se constituye a partir de un proceso de feminización degradante, el sujeto debe resistir una vida llena de tormentos, cercada por la muerte y el crimen-; por otra parte, novelas como Buen Criollo, Pasión y muerte del cura Deusto, El ángel de Sodoma y Hombres sin mujer estructuran representaciones capaces de adentrarse en la interioridad del sujeto, de reflejar su dolor y desesperación ante un amor que no puede concretarse, con una mirada que aborda al sujeto excluido - por su sexualidad, pero también por su condición social y racial-, lo que aleja a estas novelas de "la reducción y la simplificación", rasgos que se les atribuyen a los primeros archivos ficcionales del sujeto homosexual. La influencia del poder disciplinario, estructurado en torno a la heteronorma, indudablemente continúa imponiéndose con fuerza (Estenoz, 2000, p. 6). Los relatos mencionados visibilizan las relaciones de fuerza que se establecen entre posiciones de deseo homoerótico y poderes que defienden la heteronormatividad. Nuestra lectura, que ha privilegiado el comentario de textos y el diálogo con la crítica especializada, se centró por ello en la constitución del sujeto homosexual a partir de su interacción con el poder disciplinario. El sujeto homosexual oscila incansablemente entre un estado de docilidad (sostenido en una autorepresión) y uno de insubordinación 
(que comienza con el despliegue del deseo homoerótico), desarrollados bajo la atenta mirada de instituciones disciplinarias como el ejército, la cárcel, las órdenes religiosas y la familia. Podemos plantear algo similar respecto del dispositivo novela que opera también, en la etapa dominada por la estética realista, sobre la base de la inclusión y exclusión de deseos que afectan el orden disciplinario. Los textos literarios que no pueden contener posiciones de deseo homoerótico coinciden, por lo mismo, con la crisis de los binarismos fundamentales de las sociedades normalizadoras y con la fractura estructural de las ficciones miméticas, problema que dejamos planteado, pero que no podemos profundizar en este artículo.

Buen criollo inserta a Amaro en el régimen disciplinario de la marina, caracterizado por un marcado machismo, la preferencia por el castigo físico y la imagen del cuerpo como medio de adiestramiento; Buen criollo encarna al buen salvaje, despojado de toda amenaza, así como al sujeto incorregible, transformación conflictiva promovida por la separación ocurrida entre Amaro y Aleixo. Su adscripción al modelo clásico de masculinidad no logra debido a ello sostener una posición que palidece en términos sexuales y étnicos frente a la poderosa imagen simbólica que supone el joven grumete.

Los cuarenta y uno... expone el sometimiento del 'monstruo' ante el poder estatal/policial, sustentado en un sistema jurídico definido en torno al ambiguo rótulo de 'ofensa a la moral y las buenas costumbres' y la proliferación de mecanismos represivos instaurados dentro de la familia y la sociedad. Ninón refleja claramente la conflictiva construcción identitaria generada a partir de la brutal escisión que sufre el sujeto homosexual, instaurando la doble vida como la única vía posible. El rompimiento de este pacto supone la más dura condena social (injuria/infamia), provocando el castigo y la expulsión de un sujeto que se ve obligado a someterse a un proceso de reeducación total.

Pasión y muerte del cura Deusto se estructura a partir de una red de vigilancia y control sostenida por el poder eclesiástico, regidor implacable del deseo; ejerciendo una asidua violencia sobre el cuerpo del sacerdote rebelde, termina por someterlo a la muerte frente a la posibilidad de corrupción. El poder pastoral de Deusto -nuevo Jesucristo crucificado- termina por 
difuminarse ante el gitanillo de modo que ambos, oveja y pastor, terminan por perderse; si bien la existencia de estrategias de sublimación permiten la expresión del deseo, refleja claramente su necesario ocultamiento, lo que nos envía a la expulsión del signo cuerpo y del deseo de la conclusión de Juana Lucero: "Abajo, en esta charca fangosa, aguardando su restitución al polvo eterno, no queda de ella sino el capullo inútil, inconsciente, vacío de su prisionero, el mezquino calabozo de carne que sólo sirve para soñar en él con la libertad Infinita, Inmortal y Pura, mientras llega la ansiada hora de ser libre" (D’Halmar, 1902, p. 287). Pasión y muerte del cura Deusto, sin embargo, es un relato donde la tentación que produce el deseo proscrito continúa afectando los poderes dominantes. Imposible es, pues, su erradicación total.

El ángel de Sodoma problematiza la relación existente entre JoséMaría y su ciudad natal, vínculo sostenido por el recuerdo de su fallecido padre y el poder que éste ejerce sobre él. El protagonista, sometido a la vigilancia de la ciudad-panóptico, ve su cuerpo cercado por la influencia del poder disciplinario que lo obliga a mantener su propio sometimiento mediante las violencias física y psíquica que le enseñan a ejercer sobre sí mismo. Ya el título de la novela alude al relato bíblico de la ciudad de Sodoma como antecedente necesario que legitima el disciplinamiento y el castigo del sujeto.

Hombres sin mujer, erigida sobre el universo carcelario, inserta a sus personajes en una intrincada red disciplinaria. La multiplicación de un deseo siempre insatisfecho, sometido a un régimen de vigilancia y castigo, transforma al recluso en una parte de la maquinaria que tanto rechaza. El recrudecimiento del modelo de masculinidad enfrenta a los presidiarios con normas que reafirman y cuestionan una posición jerárquica alcanzada mediante la reproducción y subversión del régimen carcelario y sus códigos de conducta. Pascasio se ve atrapado en esta red que solo busca impedir el despliegue de su amor e impulsar, mediante todo un entramado de conspiraciones y mecanismos intrapenitenciarios, su muerte.

El espacio novelesco hace visible la irrupción de deseos perturbadores del orden normativo social y su colisión con determinados dispositivos disciplinarios, que activan estrategias de disolución de las alteridades que 
resisten la normalización del poder. Tres textos del corpus señalan zonas relevantes de la cartografía del deseo homoerótico que hemos intentado trazar. En Los cuarenta y uno... se alcanza la transformación y reeducación del cuerpo de Ninón, lo que implica sin dudas el triunfo del poder disciplinario. En Pasión y muerte del cura Deusto se 'neutraliza', pero no se elimina, el peligro del deseo por medio de la renuncia y el sacrificio del sacerdote, y ya no mediante el influjo del poder. En Hombres sin mujer la proliferación de mecanismos y prácticas disciplinarias muestra el fracaso del poder, que ya no puede contener la fluidez del deseo transgresivo. La literatura muestra así la imposibilidad de los sueños de los dispositivos del poder disciplinario: registrar y controlar los deseos desviados de la norma. Muestra asimismo el fracaso de las alianzas que se establecen entre la escritura novelesca y los poderes que normalizan la vida.

\section{Referencias}

Arévalo, M. (2011). Los males de la nación: sobre el buen salvaje y el otro en Buen Criollo de Adolfo Caminha. Disponible en https://issuu.com/ elescribiente/docs/los_males?backgroundColor $=\% 2523222222$

Baudrillard, J. y Guillaume, M. (2000). Las figuras de alteridad. México: Taurus.

Bejel, E. (2006). Sexualidad carcelaria en Hombres sin mujer, de Carlos Montenegro, Anales de la Literatura Española Contemporánea 31/1 (2006): 269-286. Disponible en http://www.jstor.org/stable/27742389

Bergson, H. (1943). La risa. Ensayo sobre la significación de lo cómico. Buenos Aires: Editorial Losada. 
Cabezas, A. y Berná, D. (2013) “Cuerpos, espacios y violencias en los regímenes biopolíticos de la Modernidad. De maricas y homosexuales habitando 'lo femenino"', Política y Sociedad, 50/3, 771-802. Disponible en http://revistas.ucm.es/index.php/POSO/article/view/41970

Caminha, A. (2005). Buen Criollo. Madrid: Editorial EGALES, S.L.

Castrejón, E. (seúd.) (2013). Los cuarenta y uno: novela crítico-social. México: Difusión Cultural UNAM.

Contardo, Ó. (2011). Raro. Una historia gay de Chile. Santiago de Chile: Editorial Planeta Chilena S. A.

Cornejo, J. (2009). Equívocos del lenguaje: Homoerotismo en lugar de homosexualidad, Alpha, 29, 143-154. Disponible en http:// www.scielo.cl/pdf/alpha/n29/ art10.pdf

Del Toro, J. (2015). La noche oscura: los espacios de entretenimiento y travestismo en Los 41 (1906) de Eduardo A. Castrejón (seud.). En J. C. Del Toro El cuerpo rosa. Literatura gay, homosexualidad y ciudad. Los espacios de entretenimiento de la Ciudad de México a través de la novela (pp. 61-88). Madrid: Editorial Verbum, S. L.

D'Halmar, A. (2014). Augusto D'Halmar. Obras reunidas. Santiago de Chile: Origo Ediciones.

(1902). Juana Lucero. Santiago de Chile: Imprenta, litografía y encuadernación Turín.

Domínguez, H. (2001). Augusto D'Halmar. La disolución del sujeto, Cyber Humanitatis, s/p. Disponible en http://www.revistas.uchile.cl/ index.php/RCH/article/view/8909/8785 
Estenoz, A. (2000). Tema homosexual en la literatura cubana de los 80 y los 90: ¿renovación o retroceso? Ponencia presentada en el Congreso LASA, en el panel "Queering Culture: Re-reading Latin American Identity", Miami. Disponible en http://lasa.international.pitt.edu/ Lasa2000/AlonsoEstenoz.pdf

Foucault, M. (1996). La vida de los hombres infames (Julia Valera y Fernando Álvarez, trad.). La Plata: Editorial Altamira.

(2002). Vigilar y Castigar. Nacimiento de la prisión (Aurelio Garzón del Camino, trad.). Buenos Aires: Siglo XXI Editores Argentina.

Galdo, J. C. (2000). Uso y lecciones del discurso ejemplar: a propósito de El ángel de Sodoma de Alfonso Hernández Catá, Chasqui: revista de literatura latinoamericana, 29/1, 19-32. Disponible en http://www. jstor.org/stable/29741565

Gallardo, E. (2010). Pájaros enjaulados: homosexualidad y prisión en Hombres sin mujer, Anuario de Estudios Americanos, 67/1, 107-130. Disponible en http://estudiosamericanos.revistas.csic.es/index.php/ estudiosamericanos/article/viewFile/333/338

Hernández-Catá, A. (2011). El ángel de Sodoma. USA: Stockcero.

Howes, R. (2005). Raça e sexualidade transgressiva em Bom-Crioulo de Adolfo Caminha, Revista Graphos, 7/1-2, 171-190. Disponible en http://periodicos.ufpb.br/index.php/graphos/article/view/9459/5112

Jambrina, J. (2000). Sujetos queer en la literatura cubana: hacia una (posible) genealogía homoerótica. Disponible en http://lasa.international.pitt. edu/Lasa2000/Jambrina.PDF 
Marquet, A. (2006). Castrejón, Cóccioli y Novo: La novela gay en la primera mitad del siglo XX, Literatura Mexicana, 17/2, 47-72. Disponible en http://www.redalyc.org/articulo.oa?id=358241848003

Mayer, H. (1999). Historia maldita de la literatura. Madrid: Taurus.

Mejías-López, A. (2007). Reframing Sodom: Sexuality, Nation, and Difference in Hernández Catáee El ángel de Sodoma, Ciberletras: Revista de crítica literaria y de cultura, 16, s/p. Disponible en http://www. lehman.edu/faculty/guinazu/ciberletras/v16/mejiaslopez.html

Molloy, S. (1999). Dispersiones del género: hispanismo y disidencia sexual en Augusto D'Halmar, Revista Iberoamericana, LXV / 187, 267280. Disponible en http://revistaiberoamericana.pitt.edu/ojs/index.php/ Iberoamericana/article/view/6071/6247

Monsiváis, C. (2001). Los iguales, los semejantes, los (hasta hace un minuto) perfectos desconocidos (A cien años de la Redada de los 41)" (2001). Disponible en http://www.debatefeminista.pueg.unam.mx/wp-content/ uploads/2016/03/articulos/024_17.pdf

(2013). Los 41 y la gran redada. En Castrejón E. Los cuarenta y uno: novela crítico-social. México: Difusión cultural UNAM.

Montenegro, C. (2008). Hombres sin mujer. México: Lectorum, 2008.

Nunes, C., Iturra, P., García, D. y Vera, C. (2015). Construcción de la masculinidad y la homosexualidad en $O$ bom crioulo de Adolfo Caminha, Polifonía: revista académica de estudios hispánicos, 5/1, 195-211. Disponible en http://www.apsu.edu/polifonia/v5/ 2015-nunes.pdf 
Saumell, R. Carlos Montenegro: Amor entre Pascasio y Andrés en el Castillo del Príncipe (s.f.). Disponible en http://otrolunes.com/28/estelunes/carlos-montenegro-amor-entre-pascasio-y-andres-en-el-castillodel-principe/

Tudela Sancho, A. (2012) Heteronormatividad y cuerpo sexuado: los placeres de la familia, Nuevo itinerario, Revista Digital de Filosofia, 7, 1-29. Disponible en https://ialnet.unirioja.es/servlet/ articulo? codigo $=4004767$

Villanueva-Collado, A. (1996). El puer virginal y el doble: Configuraciones arquetípicas en la Pasión y muerte del cura Deusto, por Augusto D'Halmar, Chasqui, 25/1, 3-11. Disponible en www.jstor.org/stable/ 29741250?seq=1\#page_scan_tab_contents 